ARTICLE

\title{
Modelling of Impurity Activation in the RBMK Reactor Graphite Using MCNPX
}

\author{
Rita PLUKIENE * ${ }^{*}$ Artūras PLUKIS, Andrius PUZAS, Vidmantas REMEIKIS, \\ Grigorijus DUŠKESAS and Darius GERMANAS
}

Center for Physical Sciences and Technology, Savanoriu pr. 231, LT-02300 Vilnius, Lithuania

\begin{abstract}
Numerical modelling is an important tool for estimation of the radioactive waste generation at the nuclear energy sites. In this work we have applied a Monte Carlo code, MCNPX version 2.6 for calculation of activation of the graphite stack in the RBMK-1500 reactor. The simplified 3D model of the RBMK-1500 reactor core fragment with 14 fuel assemblies and 2 control rods distributed according to the real RBMK-1500 reactor core geometry has been created.

Use of the Monte Carlo method for estimation of impurity activation in the reactor core faces a problem of large uncertainties of effective cross-sections if a calculation set is insufficient. Satisfactory results can be obtained by using parallel computing algorithms.

The ICP-MS mass spectrometry for identification of the impurity concentration in virgin graphite from the RBMK-1500 reactor has been performed to support MCNPX modelling of the realistic neutron irradiation conditions of the graphite. Simulated radiological characteristics of the graphite have been compared with the previous calculations made with different impurity concentrations obtained by neutron activation analysis and GDMS. The analysis of radioactive impurity content shows that ${ }^{14} \mathrm{C},{ }^{60} \mathrm{Co},{ }^{55} \mathrm{Fe},{ }^{238} \mathrm{Pu},{ }^{241} \mathrm{Am}$ and ${ }^{244} \mathrm{Cm}$ make the major contribution to graphite activity and radiotoxicity during hundreds of years. The obtained results are important for decommissioning of the Ignalina NPP and other NPP with RBMK type reactors.
\end{abstract}

KEYWORDS: MCNPX modelling, RBMK-1500 reactor, graphite activation, mass spectrometry

\section{Introduction}

Graphite is an important material used to moderate neutrons in nuclear reactors. Nuclear graphite is a very pure material but still contains some impurities of various elements due to graphite fabrication technology. ${ }^{1)}$ These impurities (usually $<0.01 \%$ ) are activated by $(n, \gamma)$, (n, p), (n, $\alpha)$ reactions during the long-lasting neutron irradiation period (20-30 years) partially resulting in long-lived elements (e.g. ${ }^{14} \mathrm{C},{ }^{36} \mathrm{Cl}$, transuranium elements). Decommissioning of old reactors and use of graphite planned in the new ones force to look for solutions of irradiated graphite management. Comprehensive description of the activated radionuclide composition directly influences the choice of dismantling and residue management technologies, which allows the minimization of volumes of radioactive waste and cost of its management.

There are two graphite moderated, boiling water-cooled RBMK-1500 reactors at the Ignalina site in the North-Eastern part of Lithuania. The reactors in both units contain about 3,600 t of graphite. ${ }^{2)}$ Unit 1 was operated in 1984-2004, and Unit 2 - in 1987-2009. The concentration of activation products in the RBMK-1500 reactor graphite depends strongly on the neutron flux during reactor performance, i.e. on the initial nuclide composition, burnup conditions and reactor power history. The estimation of im-

\footnotetext{
*Corresponding author, E-mail:rita@ar.fi.lt
}

(C) 2011 Atomic Energy Society of Japan, All Rights Reserved. purity activation for some radionuclide depends on uncertainty due to different neutron effective cross-section libraries used by computer codes. ${ }^{3)}$ The calculation result depends significantly on the initial impurity concentration.

Numerical modelling is an important tool for estimation of the radioactive waste generation in the nuclear reactors. ${ }^{1,4-6)}$ In this work we applied a Monte Carlo code, MCNPX version 2.6 for calculation of activation of the graphite stack in the RBMK-1500 reactor. The simplified 3D model of the RBMK-1500 reactor core fragment with 14 fuel assemblies and 2 control rods distributed according to the real RBMK-1500 reactor core geometry was created. This model represents the plateau region of active core and characterizes the realistic graphite activation. The impurities of graphite of the RBMK-1500 reactor were investigated by inductively coupled plasma mass spectrometry (ICP-MS) experimental technique and the measured concentrations were used for activation calculation. Influence of impurity activation on the difference between radionuclide specific activities in graphite sleeve and stack constructions was estimated. The comparison of simulated radiological characteristics of the graphite has been done with the previous calculations which were based on different impurity concentrations obtained by neutron activation analysis and glow discharge mass spectroscopy (GDMS). ${ }^{1)}$ In the aforementioned paper an explicit modelling of the RBMK-1500 reactor core geometry and quantitative analysis of the content of radioactive impurities in the graphite are reported. ${ }^{1)}$ It 
is difficult to compare correctly both models due to the different fuel enrichment and burnup used. The thermal neutron flux part is approximately $3 \%$ higher in the full reactor case compared with the simplified approximation. However, from the point of view of evaluation of impurity activation the uncertainties of experimental measurements in the graphite sleeve are higher than the difference between two models.

\section{Methodology}

\section{RBMK Reactor Core Modelling Details}

The model takes into account the detailed geometrical parameters of fuel assemblies, control rods and the graphite sleeve/stack constructions of the RBMK-1500 reactor. ${ }^{2)}$

A neutron population at each burnup step is 50,000 and statistical errors for calculated thermal neutron flux and total neutron flux are $0.5 \%$ and $0.3 \%$, respectively. Statistical errors of calculated specific activities are of the order of $1 \%$. The constant fuel assembly power of $2.53 \mathrm{MW}$ (which corresponds to $4200 \mathrm{MW}$ of full reactor power) was used during all irradiation time. The RBMK-1500 reactors operated for 20 and 22 years each, this results in approximately 18 years of full power days if the outage of each unit (approximately 2 months each year) is omitted. In this work the $\mathrm{UO}_{2}$ fuel enriched to $2.4 \%$ of ${ }^{235} \mathrm{U}$ and to $0.41 \%$ of burnable erbium poison was modelled. The neutron flux and reaction cross-sections were calculated after 18 years (real operational time excluding outage) of irradiation (a 220 days' time step) assuming the average burnup $12.43 \mathrm{MWd} / \mathrm{kg}$ for ${ }^{235} \mathrm{U}$ $2.4 \%(+0.41 \% \mathrm{Er})$ enrichment fuel in the RBMK-1500 reactor core. The graphite and cooling water temperatures were taken equal to $800 \mathrm{~K}$ and $550 \mathrm{~K}$, respectively, which correspond to the averaged operating conditions of the RBMK-1500 reactor at the plateau region. The graphite temperature in the upper and bottom reflectors was $620 \mathrm{~K}$. The density of the cooling water in our model is equal to $0.5 \mathrm{~g} / \mathrm{cm}^{3}$ (as the averaged density of the cooling water which in reality changes from 1 to $0.1 \mathrm{~g} / \mathrm{cm}^{3}$ starting from the bottom to the top of fuel channel) and that of graphite $1.675 \mathrm{~g} / \mathrm{cm}^{3}$. It was accepted that the active height of the fuel assembly is $686 \mathrm{~cm}$. The axial distribution of power in the RBMK-1500 reactor has also been considered. ${ }^{7)}$

We have used a simplified 3D model (see a horizontal section of the model in Fig. 1) of the RBMK-1500 reactor core fragment with 14 fuel assemblies and 2 CPS (Control and Protection System) rods distributed according to the real RBMK-1500 reactor core. The cross sectional view of one fuel assembly is presented in Fig. 2. A graphite sleeve is designed to fill the space between a fuel channel and a moderator. The periodical boundary condition was applied for side walls of the reactor segment, which corresponds to an infinite lattice comprised of such segments. The condition is suitable for modelling of neutron fluxes in the reactor constructions at the plateau part of a core. Our approach is sufficient to characterize the realistic graphite activation. The neutron fluxes were calculated in the graphite stack sleeves around the fuel assemblies and around the CPS rods. Moreover, the bottom (a lower part of $50 \mathrm{~cm}$ height) and the

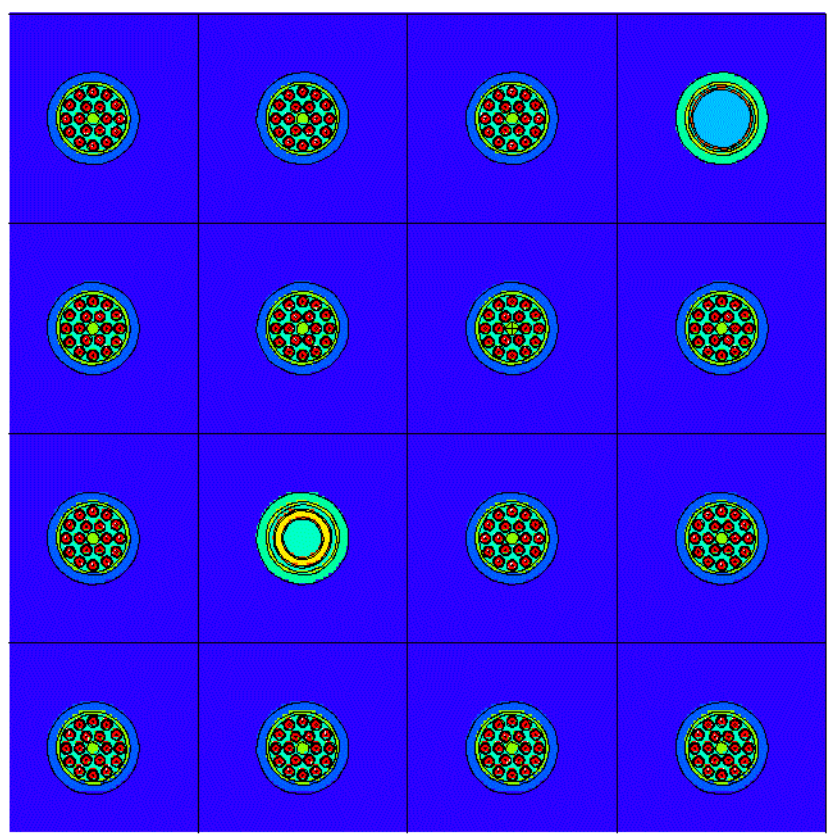

Fig. 1 3D model of RBMK-1500 reactor fragment with 14 fuel assemblies and 2 control rods

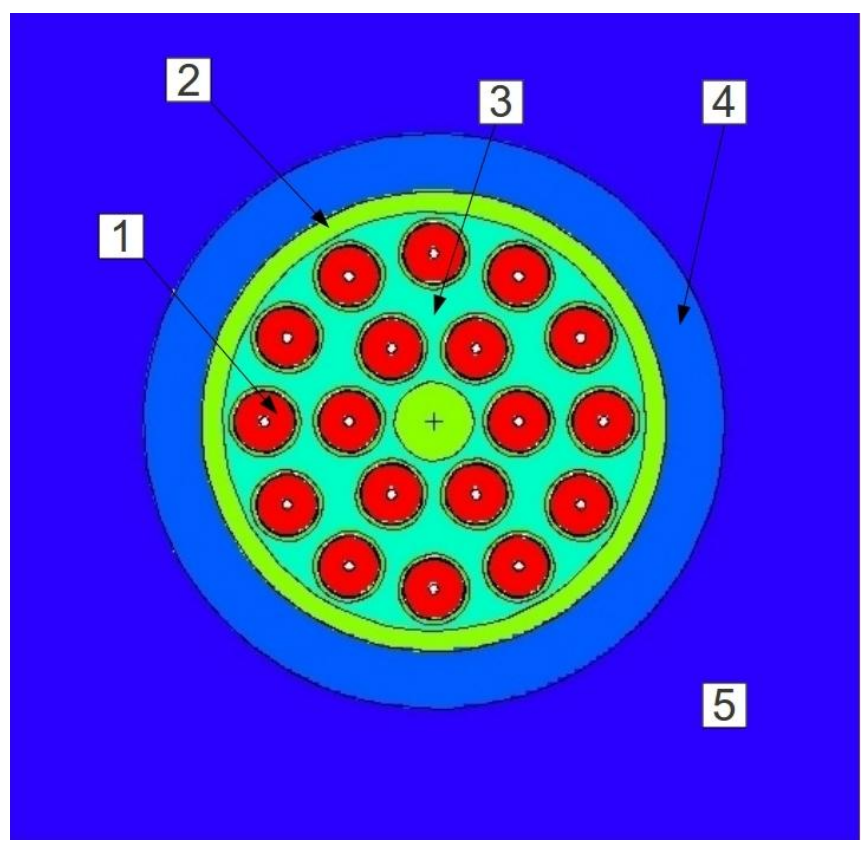

Fig. 2 One fuel assembly in the graphite matrix: $1-\mathrm{UO}_{2}$ fuel with $\mathrm{Zr}+1 \mathrm{wt} . \% \mathrm{Nb}$ cladding, 2 - fuel channel tube from $\mathrm{Zr}+2.5 \mathrm{wt} . \% \mathrm{Nb}, 3$ - coolant water, 4 - graphite sleeve, 5 graphite stack

top (an upper part of $50 \mathrm{~cm}$ height) reflectors of the core fragment have been considered. The graphite near the CPS channel was investigated supposing one inserted CPS rod with neutron absorbent $\mathrm{Dy}_{2} \mathrm{TiO}_{5}$ (in the middle part of the core fragment in Fig. 1) and one extracted CPS rod (in the corner of the core fragment in Fig. 1), which is modelled as a CPS channel filled with water and a graphite displacer. 
An automatic-cyclic coupling of MCNPX has been used for estimation of nuclide quantities in the irradiated RBMK-1500 core graphite. ${ }^{8,9)}$ Monte Carlo N-particle algorithm is applied for calculation of neutron transport. The burnup calculation in MCNPX is implemented by including the burnup code CINDER, ${ }^{10)}$ which uses 63 neutron energy groups and normalizes MCNPX tallies according to power (in the 14 fuel assemblies in our case). The ENDF/B-VII nuclear data library is used for calculation of neutron flux and cross-sections. Therefore, burnup, fuel isotopic composition, activation, and radioactive decay during irradiation are simulated with the CINDER code.

MCNPX is well suited to solve complicated three-dimensional and time-dependent problems. It was used for modelling of GT-MHR (Gas Turbine - Modular Helium cooled Reactor) in the case of plutonium (uranium free) fuel cycle and in benchmark calculations of isotopic composition of the RBMK-1500 spent nuclear fuel., ${ }^{4,5}$ MCNPX was validated by calculating and measuring carbon activation in graphite samples from the middle of the channel, the upper and bottom reflectors of the RBMK-1500 reactor (i.e. from vertical cross-section of the reactor plateau region). ${ }^{11)}$

The variability of neutron flux (i.e. variable macroscopic cross-sections) in particular graphite constructions (graphite stack, graphite sleeve) was taken into account to increase quality of radiological characterization of the graphite.

As an input data MCNPX requires detailed geometry description, nuclear data, materials and impurities in the materials. Quantitative analysis of the radioactive impurity content in the RBMK-1500 core graphite was similarly performed in the previous work. ${ }^{1)}$

Parallel algorithm was used for speeding up Monte Carlo neutron transport and nuclide transmutation calculations. MCNPX allows running multiple processes for the same task using a MPI protocol. In the present work the MS Windows MPICH2 implementation version 1.2.1.p1 was used as a MPI platform for MCNPX tasks.

\section{Impurity Concentrations of RBMK Graphite}

The impurities of the RBMK graphite were measured by the ICP-MS technique. The sample was taken from an unirradiated sleeve ring of the RBMK-1500 reactor channel. A piece of graphite was poured with $10 \mathrm{ml}$ of p.a. grade $2 \%$ nitric acid (for $72 \mathrm{~h}$ ), then diluted up to $15 \mathrm{ml}$ with distilled water assuming that impurities should wash out from the porous material - the graphite sample. ICP-MS measurements were performed with double focusing high resolution sector field inductively coupled plasma mass spectrometer Element 2 (Thermo Scientific). Optimization and calibration of the spectrometer was done using Multi-element standard solution VI Certi PUR (Merc, Darmstadt, Germany) at the concentration of $1 \mathrm{ng} \mathrm{g}^{-1}$ for the solution-based analysis. The concentration of 38 elements was measured. The values of concentration are presented in Table 1. The measured values were compared with values obtained by the neutron activation analysis technique. ${ }^{1)}$ Only a few elements such as $\mathrm{Na}, \mathrm{V}$, $\mathrm{Zn}, \mathrm{Ag}$ showed different results, besides, important impurity elements such as $\mathrm{Li}, \mathrm{S}, \mathrm{Nb}, \mathrm{Pb}$ which cannot be quantified
Table 1 Impurity concentration in the graphite sleeve sample

\begin{tabular}{clll}
\hline Isotope & $\begin{array}{c}\text { Concentration } \\
(\mathrm{ppm})\end{array}$ & Isotope & \multicolumn{1}{c}{$\begin{array}{c}\text { Concentration } \\
(\mathrm{ppm})\end{array}$} \\
\hline $\mathrm{Li}$ & $0.040 \pm 0.005$ & $\mathrm{Zn}$ & $2.6 \pm 0.1$ \\
$\mathrm{~B}$ & $5.7 \pm 0.1$ & $\mathrm{Ga}$ & $0.004 \pm 0.002$ \\
$\mathrm{Na}$ & $37.1 \pm 1.5$ & $\mathrm{Sr}$ & $0.83 \pm 0.05$ \\
$\mathrm{Mg}$ & $2.8 \pm 0.4$ & $\mathrm{Zr}$ & $0.57 \pm 0.04$ \\
$\mathrm{Al}$ & $11.2 \pm 0.3$ & $\mathrm{Nb}$ & $0.006 \pm 0.001$ \\
$\mathrm{Si}$ & $68.0 \pm 4.8$ & $\mathrm{Mo}$ & $0.06 \pm 0.02$ \\
$\mathrm{P}$ & $0.66 \pm 0.02$ & $\mathrm{Ag}$ & $0.06 \pm 0.01$ \\
$\mathrm{~S}$ & $6.8 \pm 0.2$ & $\mathrm{Cd}$ & $0.04 \pm 0.01$ \\
$\mathrm{Cl}$ & $15.5 \pm 1.2$ & $\mathrm{Sn}$ & $0.14 \pm 0.02$ \\
$\mathrm{~K}$ & $23.4 \pm 0.5$ & $\mathrm{Cs}$ & $0.002 \pm 0.001$ \\
$\mathrm{Ca}$ & $79.3 \pm 3.2$ & $\mathrm{Ba}$ & $1.31 \pm 0.02$ \\
$\mathrm{Ti}$ & $4.0 \pm 0.2$ & $\mathrm{Eu}$ & $0.002 \pm 0.001$ \\
$\mathrm{~V}$ & $0.20 \pm 0.01$ & $\mathrm{Ho}$ & $0.002 \pm 0.002$ \\
$\mathrm{Cr}$ & $0.49 \pm 0.03$ & $\mathrm{Hf}$ & $0.014 \pm 0.003$ \\
$\mathrm{Mn}$ & $0.62 \pm 0.02$ & $\mathrm{~W}$ & $0.037 \pm 0.004$ \\
$\mathrm{Fe}$ & $41.4 \pm 1.7$ & $\mathrm{~Pb}$ & $2.1 \pm 0.2$ \\
$\mathrm{Co}$ & $0.035 \pm 0.004$ & $\mathrm{Bi}$ & $0.002 \pm 0.001$ \\
$\mathrm{Ni}$ & $0.61 \pm 0.03$ & $\mathrm{Th}$ & $0.003 \pm 0.001$ \\
$\mathrm{Cu}$ & $0.66 \pm 0.02$ & $\mathrm{U}$ & $0.006 \pm 0.001$ \\
\hline
\end{tabular}

by neutron activation method, were obtained by the ICP-MS measurements.

The concentration values were used for the graphite waste radiological characterization. Unfortunately, some of the important graphite impurities could not be measured by ICP-MS method due to sample preparation process (for example, ${ }^{14} \mathrm{~N}$ was immeasurable because the matrix of the sample was digested with nitric acid). Concentrations of ${ }^{13} \mathrm{C}$ and ${ }^{14} \mathrm{~N}$ isotopes as well as a problem of variation of carbon activation in the reactor graphite were analysed in the previous work. ${ }^{11)}$ Nitrogen is used to flush the graphite stack of the RBMK reactors; therefore its activation is inhomogeneous on the surface and inside of the graphite. The impurities of ${ }^{14} \mathrm{~N}$ in the graphite stack comprise $0.5-70 \mathrm{ppm}$ as reported previously. ${ }^{1)}$ In this work we have used $15 \pm 4$ ppm value, the same as in our antecedent paper. ${ }^{11)}$

\section{Results and Discussion}

The fuel assemblies in the RBMK reactor are replaced on line. This results in constant average burnup and almost constant neutron flux in the core. In our model simulation of the irradiation of the impurities in the graphite constructions was done supposing constant averaged fuel burnup in the fuel assemblies. The averaged value of the neutron flux calculated with MCNPX is $1.55 \cdot 10^{14} \mathrm{n} / \mathrm{cm}^{2} \cdot \mathrm{s}$ and $1.61 \cdot 10^{14}$ $\mathrm{n} / \mathrm{cm}^{2} \cdot \mathrm{s}$ in the graphite sleeve and the graphite stack, respectively. The value of the averaged neutron flux in the bottom and top parts of the graphite reflector (in the volume of $50 \mathrm{~cm}$ above and below the core, respectively) is equal to $1.14 \cdot 10^{13} \mathrm{n} / \mathrm{cm}^{2} \cdot \mathrm{s}$. Good agreement between modelled and measured values of the change of a ratio of concentrations $\delta\left(\left[{ }^{13} \mathrm{C}\right] /\left[{ }^{12} \mathrm{C}\right]\right)$ in the irradiated and virgin graphite for the central part of the reactor core indicates that the neutron flux is modelled accurately. ${ }^{11)}$ The neutron spectrum in the graphite does not change considerably during the irradiation time as it can be observed in Fig. 3. The neutron spectrum 


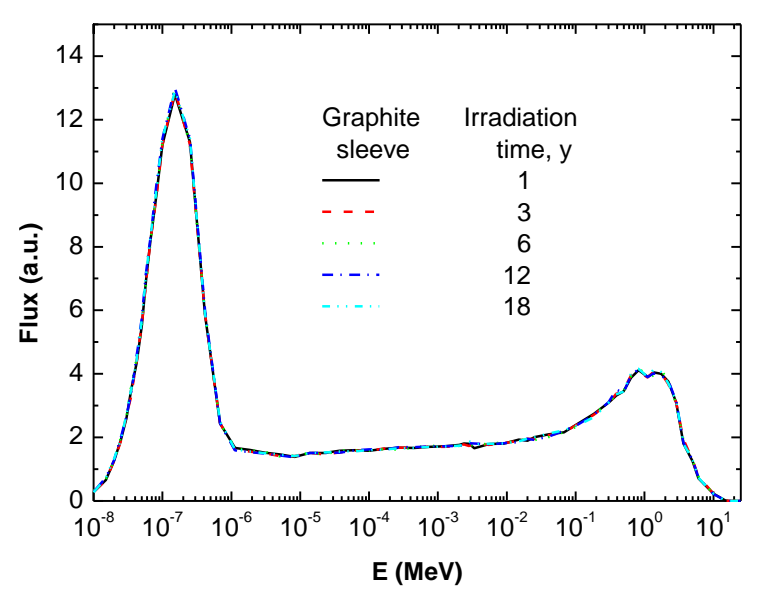

Fig. 3 The spectra of neutron flux in the RBMK-1500 reactor graphite sleeve at different irradiation time

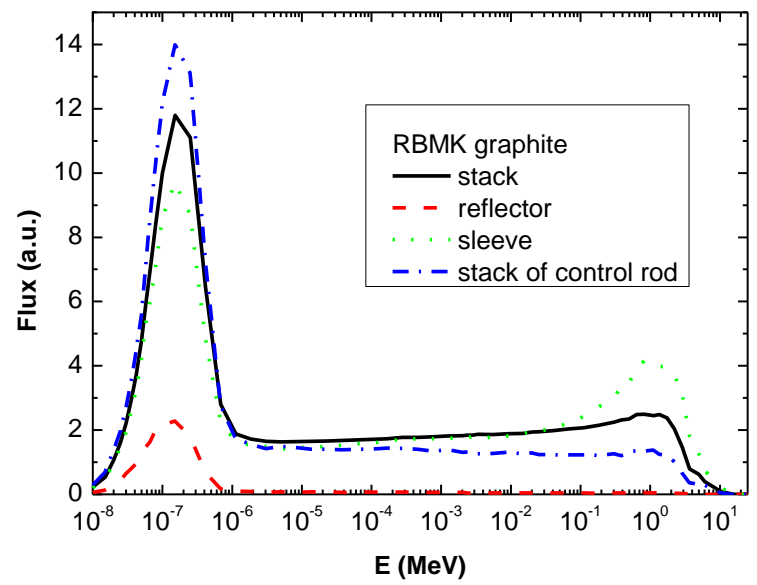

Fig. 4 The spectra of neutron flux in different graphite constructions of the RBMK-1500 reactor fragment

depends on the graphite spatial location in the reactor as it is presented in Fig. 4.

The measured impurity concentrations (provided in Table 1) were used for the neutron activation calculation in the graphite by MCNPX. The most important radionuclides, taking into account their half-lives and activities, are presented in Table 2. ${ }^{137} \mathrm{Cs},{ }^{90} \mathrm{Sr},{ }^{125} \mathrm{Sb}$, etc. appear due to fission of uranium and thorium impurities in the graphite. $U$ is also responsible for the presence of transuranium isotopes in the graphite.

Here we present the calculated results for the irradiated graphite sleeve activation, which are based on the experimentally measured impurities in virgin graphite of the particular construction part.

Specific activities of radionuclide in the graphite sleeve as a function of irradiation time are presented in Fig. 5. One can observe that the most of long-lived nuclides $\left({ }^{60} \mathrm{Co},{ }^{90} \mathrm{Sr}\right.$, ${ }^{137} \mathrm{Cs},{ }^{41} \mathrm{Ca},{ }^{59} \mathrm{Ni},{ }^{36} \mathrm{Cl}$, etc.) are accumulated in the first few years, and after that their concentration is almost a constant. The different behaviour is observed for Eu isotopes, which are produced by the double neutron capture reaction ${ }^{153} \mathrm{Eu}(\mathrm{n}, \gamma) \rightarrow{ }^{154} \mathrm{Eu}(\mathrm{n}, \gamma) \rightarrow{ }^{155} \mathrm{Eu}$ and also due to fission of $\mathrm{U}$
Table 2 Neutron activation reactions of impurities in graphite

\begin{tabular}{cccc}
\hline $\begin{array}{c}\text { Parent } \\
\text { nuclide }\end{array}$ & $\begin{array}{c}\text { Reaction } \\
\text { type }\end{array}$ & $\begin{array}{c}\text { Daughter } \\
\text { nuclide }\end{array}$ & Half-life \\
\hline${ }^{6} \mathrm{Li}$ & $\mathrm{n}, \alpha$ & ${ }^{3} \mathrm{H}$ & $12.3 \mathrm{y}$ \\
${ }^{13} \mathrm{C}$ & $\mathrm{n}, \gamma$ & ${ }^{14} \mathrm{C}$ & $5730 \mathrm{y}$ \\
${ }^{14} \mathrm{~N}$ & $\mathrm{n}, \mathrm{p}$ & ${ }^{14} \mathrm{C}$ & $5730 \mathrm{y}$ \\
${ }^{35} \mathrm{Cl}$ & $\mathrm{n}, \gamma$ & ${ }^{36} \mathrm{Cl}$ & $3.01 \cdot 10^{5} \mathrm{y}$ \\
${ }^{39} \mathrm{~K}$ & $\mathrm{n}, \mathrm{p}$ & ${ }^{39} \mathrm{Ar}$ & $269 \mathrm{y}$ \\
${ }^{40} \mathrm{Ca}$ & $\mathrm{n}, \gamma$ & ${ }^{41} \mathrm{Ca}$ & $1.03 \cdot 10 \mathrm{y}$ \\
${ }^{44} \mathrm{Ca}$ & $\mathrm{n}, \gamma$ & ${ }^{45} \mathrm{Ca}$ & $162 \mathrm{~d}$ \\
${ }^{54} \mathrm{Fe}$ & $\mathrm{n}, \gamma$ & ${ }^{55} \mathrm{Fe}$ & $2.73 \mathrm{y}$ \\
${ }^{56} \mathrm{Fe}$ & $\mathrm{n}, 2 \mathrm{n}$ & ${ }^{55} \mathrm{Fe}$ & $2.73 \mathrm{y}$ \\
${ }^{58} \mathrm{Fe}$ & $\mathrm{n}, \gamma$ & ${ }^{59} \mathrm{Fe}$ & $44.5 \mathrm{~d}$ \\
${ }^{58} \mathrm{Ni}$ & $\mathrm{n}, \gamma$ & ${ }^{59} \mathrm{Ni}$ & $7.6 \cdot 10^{5} \mathrm{y}$ \\
${ }^{59} \mathrm{Ni}$ & $\mathrm{n}, \mathrm{p}$ & ${ }^{58} \mathrm{Co}$ & $70.8 \mathrm{y}$ \\
${ }^{62} \mathrm{Ni}$ & $\mathrm{n}, \gamma$ & ${ }^{63} \mathrm{Ni}$ & $101.1 \mathrm{y}$ \\
${ }^{59} \mathrm{Co}$ & $\mathrm{n}, \gamma$ & ${ }^{60} \mathrm{Co}$ & $5.27 \mathrm{y}$ \\
${ }^{107} \mathrm{Ag}$ & $\mathrm{n}, \gamma$ & ${ }^{108 m} \mathrm{Ag}$ & $418 \mathrm{y}$ \\
${ }^{133} \mathrm{Cs}$ & $\mathrm{n}, \gamma$ & ${ }^{134} \mathrm{Cs}$ & $2.065 \mathrm{y}$ \\
${ }^{151} \mathrm{Eu}$ & $\mathrm{n}, \gamma$ & ${ }^{152} \mathrm{Eu}$ & $13.54 \mathrm{y}$ \\
${ }^{153} \mathrm{Eu}$ & $\mathrm{n}, \gamma$ & ${ }^{154} \mathrm{Eu}$ & $8.59 \mathrm{y}$ \\
\hline
\end{tabular}

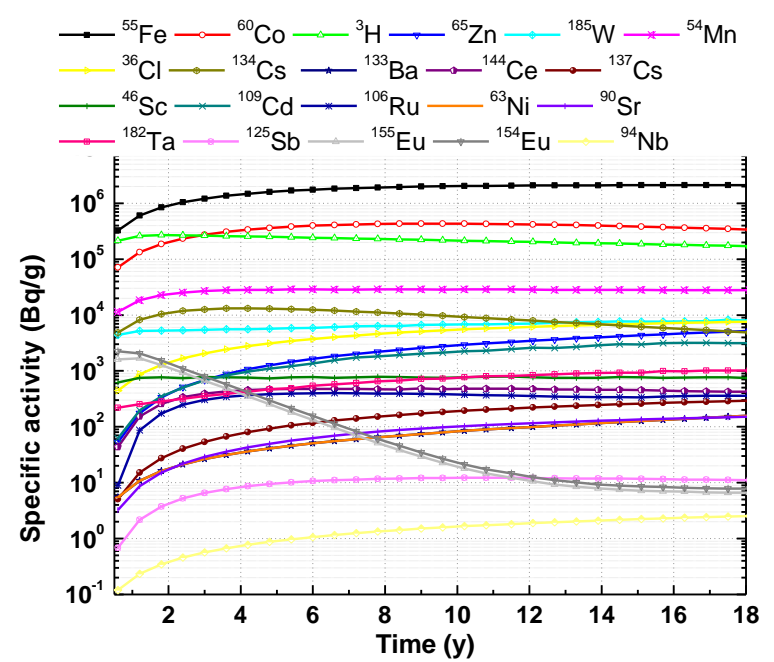

Fig. 5 Specific activities of radionuclide as a function of irradiation time

and Th. In the first 6-8 years the diminishing of ${ }^{154} \mathrm{Eu}$ and ${ }^{155} \mathrm{Eu}$ is caused by the $(\mathrm{n}, \gamma)$ reaction and the later incline is determined by the replenishment of ${ }^{153} \mathrm{Eu}$ and ${ }^{155} \mathrm{Eu}$ from fission of actinides. Other nuclides having high neutron capture cross-sections in the thermal flux are burnt (for instance, $\left.{ }^{134} \mathrm{Cs}\right) .{ }^{55} \mathrm{Fe},{ }^{60} \mathrm{Co},{ }^{3} \mathrm{H}$, and ${ }^{14} \mathrm{C}$ make the major input to the graphite activity. Simulated activity of ${ }^{14} \mathrm{C}$ was compared with the one measured by the $\beta$ spectrometry technique. ${ }^{11)}$

Concerning the graphite sleeve and stack constructions, the difference of radionuclide specific activities due to impurity activation is not considerable (less than 15\%) for the most of radionuclides, and the total activity is about $10 \%$ higher in the graphite stack. However, for some isotopes, which are sensitive to the neutron flux energy distribution the difference is bigger. It is more than $20 \%$ (for ${ }^{154-155} \mathrm{Eu}$, 


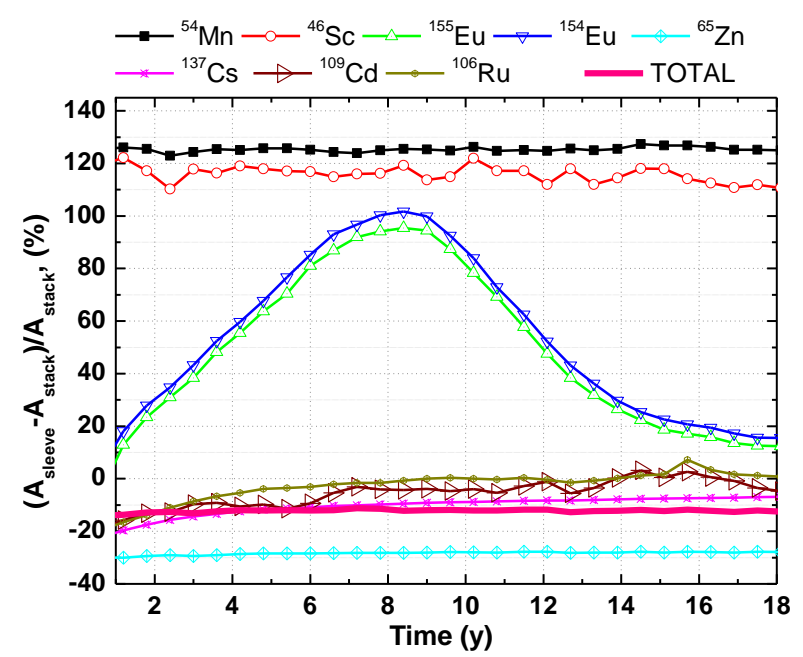

Fig. 6 Difference of specific activities of radionuclides in graphite sleeve and stack as a function of irradiation time

${ }^{65} \mathrm{Zn},{ }^{137} \mathrm{Cs},{ }^{109} \mathrm{Cd},{ }^{106} \mathrm{Ru}$ ) and even up to a few times (for ${ }^{54} \mathrm{Mn},{ }^{46} \mathrm{Sc}$ ) as it can be seen in Fig. 6. The biggest differences appear for nuclides which are produced by fast neutrons via (n,p) reaction (i. e. ${ }^{54} \mathrm{Mn},{ }^{46} \mathrm{Sc}$ production from ${ }^{54} \mathrm{Fe}$ and ${ }^{46} \mathrm{Ti}$ ). The activity of ${ }^{154} \mathrm{Eu}$ and ${ }^{155} \mathrm{Eu}$ is higher in the graphite stack compared with the sleeve and has complicated behaviour in the middle of irradiation time due to different production channels as it was discussed before. The activity of ${ }^{65} \mathrm{Zn}$ is lower in the graphite sleeve, which is caused by disappearance of ${ }^{65} \mathrm{Zn}$ by the ${ }^{65} \mathrm{Zn}(\mathrm{n}, \gamma) \rightarrow{ }^{66} \mathrm{Zn}$ reaction, which prevails in epithermal neutron flux. ${ }^{108} \mathrm{Cd}(\mathrm{n}, \gamma) \rightarrow{ }^{109} \mathrm{Cd}$ reaction is responsible for more than $20 \%$ higher ${ }^{109} \mathrm{Cd}$ activity in the graphite stack at the beginning of irradiation and after 8 years of irradiation the difference disappears. ${ }^{137} \mathrm{Cs}$ and ${ }^{106} \mathrm{Ru}$ come from the actinide fission and more depend on the thermal neutron flux similarly as fissionable actinides (see Fig. 7).

The difference of actinide specific activities in the graphite sleeve and graphite stack as a function of irradiation time is presented in Fig. 7. The total activity of actinides is about $12 \%$ higher in the graphite stack compared with the graphite sleeve - this is influenced by the higher thermal neutron flux in the graphite stack. The specific activity of $\mathrm{Pu}$ isotopes and ${ }^{241} \mathrm{Am}$ is less in the sleeve at the beginning of irradiation and higher at the end of the irradiation. The highest differences (up to $50 \%$ at the end of irradiation) are observed for ${ }^{241} \mathrm{Am}$, which has high neutron capture cross-section in the thermal neutron region, and which is also produced from ${ }^{241} \mathrm{Pu} \beta$ decay. The generation and disappearance of actinides are processes which depend on the neutron flux, its energy distribution and nuclide effective cross-sections. The specific activity of the $\mathrm{Cm}$ isotopes and ${ }^{243} \mathrm{Am}$ is higher in the graphite stack at the beginning of irradiation and almost equalizes at the end of irradiation. Despite the fact that difference of radionuclide specific activities due to impurity activation in the graphite sleeve and stack constructions is not considerable (less than 15\%) for most of them, but small difference can become crucial estimating the radionuclides which are on the clearance levels limit; for instance, concentration of

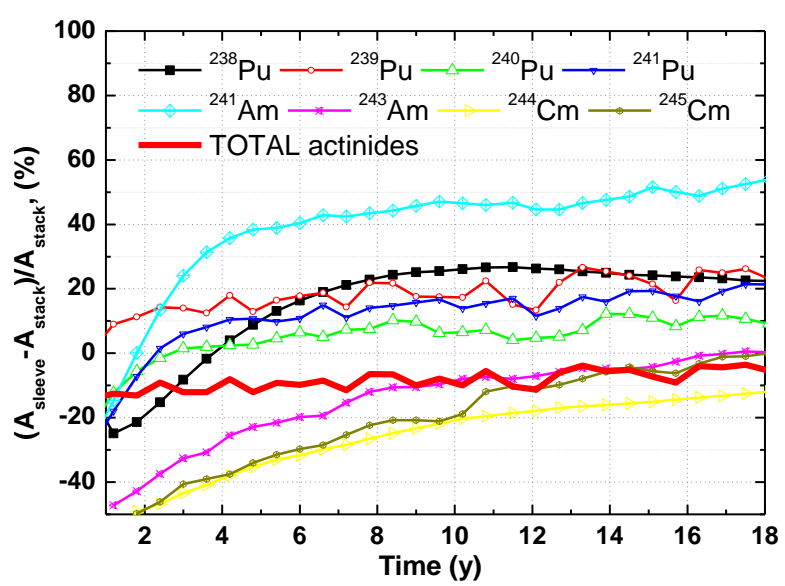

Fig. 7 Difference of specific activities of actinides in the graphite sleeve and stack as a function of irradiation time

${ }^{239} \mathrm{Pu}$ in the stack is below the clearance level but in the sleeve its $22 \%$ higher activity is on the limit (see also Fig. 8 for more details).

The specific activities of other radionuclides which exceed or are close to their clearance level (according to Lithuanian norms) as a function of the cooling time are shown in Fig. 9. The highlighted lines and the notes on right of the lines indicate clearance levels for individual radionuclides. The total activity decreases sharply after shutdown of the reactor because of the decay of short-lived nuclides, while after 10 years of cooling it changes very slowly for a long time.

${ }^{14} \mathrm{C}$ and ${ }^{3} \mathrm{H}$ compose the long-term radiotoxicity of graphite waste, while ${ }^{55} \mathrm{Fe},{ }^{60} \mathrm{Co},{ }^{65} \mathrm{Zn},{ }^{54} \mathrm{Mn},{ }^{36} \mathrm{Cl}$ are important for dismantling on the site. ${ }^{109} \mathrm{Cd},{ }^{125} \mathrm{Sb},{ }^{154-155} \mathrm{Eu}$ do not exceed the clearance levels. By comparing our results based on new impurity concentrations with the previous calculations, ${ }^{1)}$ we obtain higher values for ${ }^{55} \mathrm{Fe},{ }^{36} \mathrm{Cl}$ and lower values for ${ }^{14} \mathrm{C}$ concentrations, the ${ }^{60} \mathrm{Co}$ and ${ }^{3} \mathrm{H}$ concentrations are quite similar. ${ }^{14} \mathrm{C}$ is very important for selection of the best option for waste management and a lower value of the activity is more favourable from the point of view of long-term disposal.

The specific activities of actinides as a function of the cooling time are presented in Fig. $8 .{ }^{244} \mathrm{Cm}$ and ${ }^{241} \mathrm{Pu}$ dominate at the first 100 years, afterwards until 1000 years dominates ${ }^{241} \mathrm{Am}$. We have obtained higher actinide concentration than one in the previous work. ${ }^{1)}$ New values of actinide concentration exceed unconditional clearance levels and can create an additional problem for waste management.

\section{Conclusion}

A radionuclide composition in the graphite of the RBMK-1500 reactor has been modelled with MCNPX (which includes CINDER burnup capability). Satisfactory results have been obtained by using parallel computing algorithms for calculation of a simplified $3 \mathrm{D}$ model of the RBMK-1500 reactor core fragment with 14 fuel assemblies 


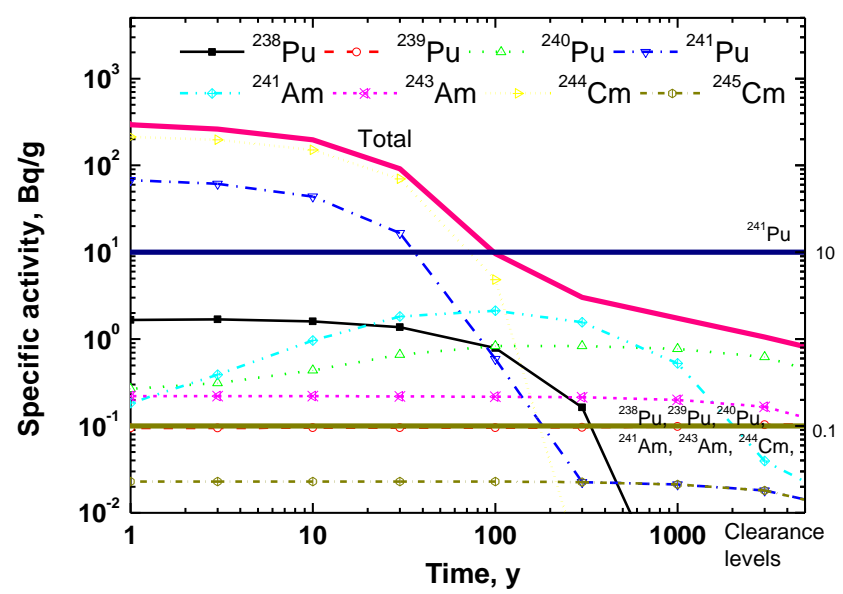

Fig. 8 Specific activities of actinides as a function of cooling time in the graphite sleeve (The clearance lines for actinides on the right in $\mathrm{Bq} / \mathrm{g}$ for listed nuclides.)

and 2 control rods. A neutron spectrum in the graphite does not depend on the fuel burnup but depends on a graphite spatial location in the reactor. A difference of radionuclide specific activities due to impurity activation in the graphite sleeve and stack constructions is not considerable (less than $15 \%$ ) for the most of radionuclides, but can affect estimation of the radionuclides which are on the clearance levels limit (for instance, ${ }^{239} \mathrm{Pu}$ concentration in the stack is below the clearance level, but in the sleeve it is on the limit). New values of the graphite impurity concentration obtained by the ICP-MS measurements have been used and simulated radioactive content of the graphite has been compared with the previous calculation made with different impurity concentrations obtained by neutron activation analysis and GDMS. ${ }^{1)}$ In the present calculation higher values for ${ }^{55} \mathrm{Fe},{ }^{36} \mathrm{Cl}$ and lower values for ${ }^{14} \mathrm{C}$ concentration are obtained, while the ${ }^{60} \mathrm{Co}$ and ${ }^{3} \mathrm{H}$ concentrations are quite similar. ${ }^{14} \mathrm{C}$ is very important for selection of the best option for waste management and a lower value of the activity is more favourable from the point of view of long-term disposal. We have obtained higher actinide concentration than one in the previous work. ${ }^{1)}$ New values of actinide concentration exceed unconditional clearance levels and can create an additional problem for waste management. The obtained results are important for decommissioning of the Ignalina NPP and other NPP with RBMK type reactors. They can be used as a basis for derivation of scaling factors for difficult-to-measure radionuclides in the irradiated graphite. ${ }^{5)}$

\section{Acknowledgment}

The research leading to these results has received funding from the European Atomic Energy Community's Seventh Framework Programme (FP7/2007-2011) under grant agreement $\mathrm{n}^{\circ} 211333$.

The work has also been supported by Agency for International Science and Technology Development Programmes in Lithuania (contract $n^{\circ} 31 \mathrm{~V}-180$ ).

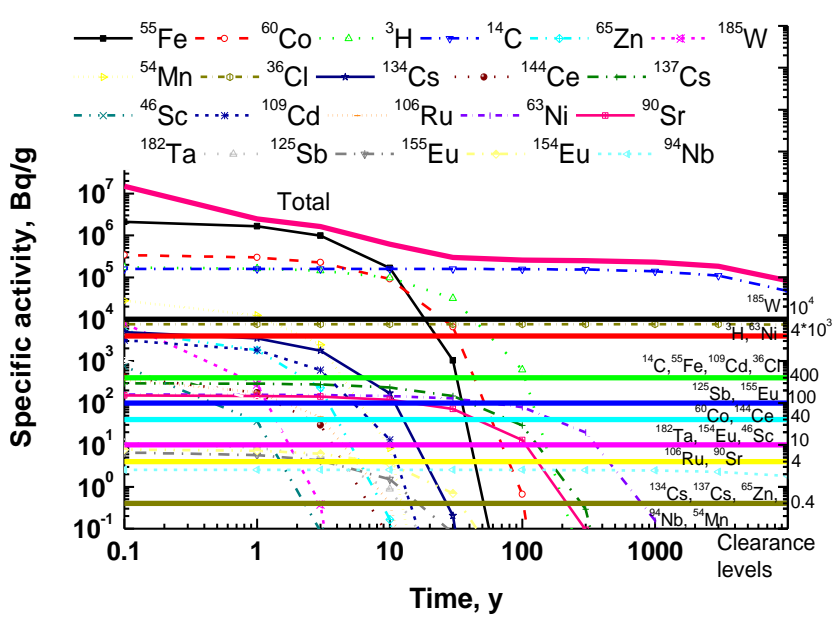

Fig. 9 Specific activities of radionuclide as a function of cooling time in the graphite sleeve (The clearance lines on the right in $\mathrm{Bq} / \mathrm{g}$ for listed nuclides.)

\section{References}

1) D. Ancius, D. Ridikas, V. Remeikis, A. Plukis, R. Plukiene, M. Cometto, "Evaluation of the activity of irradiated graphite in the Ignalina Nuclear Power Plant RBMK-1500 reactor," Nukleonika, 50, 113-120 (2005).

2) K. Almenas, A. Kaliatka, E. Ušpuras, Ignalina RBMK-1500, 2nd ed., Lithuanian Energy Institute, Kaunas, 198 p. (1998).

3) M. Cometto, D. Ancius, D. Ridikas, "Testing of different data libraries in activation analysis of concrete and graphite from nuclear installations," Proc. Int. Workshop on Nuclear Data for the Transmutation of Nuclear Waste, GSI-Darmstadt, Germany, Sept. 1-5, 2003 (2003); http://www-wnt.gsi.de/ TRAMU.

4) R. Plukiene, D. Ridikas, "Modelling of HTRs with Monte Carlo: from a homogeneous to an exact heterogeneous core with microparticles," Ann. Nucl. Eng., 30, 1573-1585 (2003).

5) V. Remeikis, A. Plukis, L. Juodis, A. Gudelis, D. Lukauskas, R. Druteikiene, G. Lujaniene, B. Luksiene, R. Plukiene, G. Duskesas, "Study of the nuclide inventory of operational radioactive waste for the RBMK-1500 reactor," Nucl. Eng. Des., 239, 813-818 (2009).

6) A. Šmaižys, E. Narkūnas, P. Poškas, "Modelling of activation processes for GR-280 graphite at Ignalina NPP," Radiat. Prot. Dosim., 116, 270-275 (2005).

7) Ignalina NPP Unit 2 Safety Analysis Report, Code of document PTOab2-0345- 5112V1, Ignalina NPP, Visaginas (2002).

8) D. B. Pelowitz, MCNPX User's Manual. Version 2.6.0, LA-CP-07-1473, Los Alamos National Laboratory (LANL) (2008).

9) M. L. Fensin, J. S. Hendricks, S. Anghaie, "The Enhancements and Testing for the MCNPX 2.6.0 Depletion Capability," Nucl.Tech., 170[1], 68-79 (2010).

10) W. B. Wilson, S. T. Cowell, T. R. England, A. C. Hayes, P. Moller, A Manual for CINDER'90 Version 07.4. Codes and Data, LA-UR-07-8412, Los Alamos National Laboratory (LANL) (2007).

11) V. Remeikis, A. Plukis, R. Plukienè, A. Garbaras, R. Barisevičiūtè, A. Gudelis, R. Gvozdaite, G. Duškesas and L. Juodis, "Method based on isotope ratio mass spectrometry for evaluation of carbon activation in the reactor graphite," Nucl. Eng. Des., 240[10], 2697-2703 (2010). 